\title{
Dynamic response of filament winding angle on complex shaped mandrels
}

\author{
DOI: 10.35530/IT.071.05.1717
}

AHMET REFAH TORUN

ABSTRACT - REZUMAT

Dynamic response of filament winding angle on complex shaped mandrels

Aerodynamic parts such as rocket nose and heat shield related composites are mainly produced with filament winding machines. Winding angle of the reinforcement filament is the main parameter to determine the thermomechanical properties of the final composite part. The angle adjustments on the machine cause the temporary response of the filaments. This study derives an analytical method to determine the real angle of the filaments on the mandrel.

Keywords: winding angle, filament winding, composite materials, conical parts, complex shape mandrels

Răspunsul dinamic al unghiului de înfășurare al filamentelor asupra poansoanelor cu forme complexe

Piesele aerodinamice, cum ar fi vârful rachetei și materialele compozite pentru scutul termic, sunt produse în principal cu mașini pentru înfășurarea filamentelor. Unghiul de înfășurare al filamentului de armare este principalul parametru pentru a determina proprietățile termomecanice ale piesei compozite finale. Reglajele unghiului pe mașină determină răspunsul temporar al filamentelor. Acest studiu descrie o metodă analitică pentru a determina unghiul real al filamentelor de pe poanson.

Cuvinte-cheie: unghi de înfășurare, înfășurarea filamentelor, materiale compozite, piese conice, poansoane cu forme complexe

\section{INTRODUCTION}

Textile reinforced composites are used for a wide range of applications. The anisotropic nature of the composite parts extends the potential of conventional materials; however, an educated design of the layers and fiber alignment are necessary to fulfill the requirements. Filament winding is the main method to produce axially symmetrical body parts from composite materials. Winding angle of the layers is the main parameter to determine the mechanical properties. Depending on the structural design and requirements of the composite part, winding angle is changed during the production. The filament angles respond with a delay to the changing machine parameters. The aim of this study is to determine the filament angle functions analytically both for constant and changing machine settings on complex shaped mandrels.

There are many studies which analyze the effects of filament angle on the mechanical properties. Spencer and Hull have shown that both the tensile and shear strength depends on the winding angles [1]. Mistry has studied the mechanical behavior in particular bending and compression stresses of filament wound composite structures under hydrostatic pressure. The effects of winding angle were shown both experimentally and via finite elements analysis. The optimum winding angle was around 80 degrees for this coupled stress condition [2]. Filament winding on conical shapes is important for the production of aerodynamical composite structures. In the literature no study is published on the temporary response of filament angle to the changing machine velocity. Kessels and Akkerman have developed a numerical method to determine the local angles on complex shaped braided structures [3]. Zhang et al. have analyzed the kinematical properties [4] and mechanical properties [5] of cylindrical braiding. Nishimoto et al. have developed an analytical method to predict the response of filaments on cylindrical braiding [6].

\section{THEORETICAL APPROACH}

\section{Cylindrical mandrel}

In this section, the equations of angle formations will be determined by starting with a simple cylindrical mandrel and the equations for complex shapes will be derived from this model. The mechanism of winding angle formation for filament winding on a cylindrical mandrel with constant speeds is depicted in fig- ure 1. The tangential angle $\alpha$ of the filament is determined by the cylinder radius $r$, angular velocity of the mandrel $w_{0}$ and lateral velocity of the filament guide $v_{0}$.

$$
\begin{gathered}
u_{0}=r w_{0} \\
\alpha=\tan ^{-1}\left(\frac{r w_{0}}{v_{0}}\right)
\end{gathered}
$$

If the angular velocity $w_{0}$ or the tangential velocity $v_{0}$ of the system is changed as a step function, it takes time for the filaments to adapt the new production conditions. This can be called as unstationary state of the system between two stationary conditions. After the new steady state is reached, the winding of filaments continues with constant angle. 
The system response for the cylindrical filament winding to velocity changes can be analyzed by dividing the cross section of the cylinder with $\theta$ small angles (figure 2). For every turning of $\theta$, the initial winding angle $\alpha_{i}$ approaches to the final winding angle $\alpha_{f}$.

In figure 2 on the right side, the first differential step leads the filament to go to the point $X_{2}$ instead of point $X_{1}$. In this case, the triangles $Y_{2} X_{2} Z$ and $\mathrm{Y}_{2} \mathrm{OC}$ are similar, therefore:

$$
\frac{|O C|}{\left|Y_{2} C\right|}=\frac{\left|X_{2} Z\right|}{\left|Z Y_{2}\right|}
$$

If the iterations of the $Y$ points are numbered as $a_{i}$ and $a_{i+1}$, the equation 3 can be constructed as:

$$
\frac{|O C|}{a_{i+1}}=\frac{r \cdot w_{0} \cdot \Delta t}{a_{i}-a_{i+1}+v_{f} \cdot \Delta t} ; \quad \Delta a=a_{i+1}-a_{i}
$$

After dividing the right hand side of the equation with $\Delta t:$

$$
\begin{gathered}
\frac{|O C|}{r \cdot w_{0}}\left[-\frac{\Delta a}{\Delta t}+v_{f}\right]=a_{i+1} ; \text { where } \frac{\Delta a}{\Delta t}=\frac{\mathrm{d} a}{\mathrm{~d} t} ; \\
a_{i+1}=a(t) ; \quad \frac{r \cdot w_{0}}{v_{f}}=\tan \alpha_{f} \\
-\frac{|O C|}{r \cdot w_{0}} \cdot \frac{\mathrm{d} a}{\mathrm{~d} t}=a(t)-\frac{|O C|}{\tan \alpha_{f}} \rightarrow \\
\rightarrow \int \frac{\mathrm{d} a}{a(t)-\frac{|O C|}{\tan \alpha_{f}}}=\int \frac{-r \cdot w_{0} \cdot \mathrm{d} t}{|O C|}
\end{gathered}
$$

The differential equation (equation 6 ) can be solved by separating variables and integrating afterwards.

$$
a(t)=C_{0} \cdot e^{-\frac{r \cdot w_{0}}{|O C|} \cdot t}+\frac{|O C|}{\tan \alpha_{f}}
$$

The boundary values are:

$$
a(0)=\frac{|O C|}{\tan \alpha_{i}} ; a(\infty)=\frac{|O C|}{\tan \alpha_{f}}
$$

After inserting boundary values into equation 7 :

$$
\begin{gathered}
a(t)=|O C| \cdot\left[\left(\tan \alpha_{i}\right)^{-1}-\left(\tan \alpha_{f}\right)^{-1}\right] . \\
\cdot e^{-\frac{r \cdot w_{0}}{|O C|} \cdot t}+\frac{|O C|}{\tan \alpha_{f}}
\end{gathered}
$$

The time dependent function of $\alpha(t)$ according to the position change $a(t)$ can be written as:

$$
\begin{gathered}
\tan \alpha(t)=\frac{|O C|}{a(t)} \\
\alpha(t)=\tan ^{-1}\left\{\left[\left[\left(\tan \alpha_{i}\right)^{-1}-\left(\tan \alpha_{f}\right)^{-1}\right] \cdot e^{-\frac{r \cdot w_{0}}{|O C|} \cdot t}+\right.\right. \\
\left.\left.+\left(\tan \alpha_{f}\right)^{-1}\right]^{-1}\right\}
\end{gathered}
$$

\section{Conical mandrel}

Filament winding on conical mandrels is used in manufacturing of aerodynamic composite structures such as rocket nose. Due to the change of mandrel radius along the length of the mandrel, the circumferential velocity of the filament changes as well. Figure 3 demonstrates the main parameters of filament winding on a conical mandrel.

The radius $r$ of cone is changing linearly along the length, which affects the circumferential velocity. Filament guide moves laterally with the velocity of $v_{0}$, however, the tangential lateral velocity of $v_{\tan }$ must be used to find the winding angle.

$$
\begin{gathered}
\cos \beta=\frac{L}{\sqrt{\left(R-r_{0}\right)^{2}+L^{2}}} \\
\frac{\Delta r}{v_{0} \cdot t}=\tan \beta=\frac{R-r_{0}}{L}
\end{gathered}
$$




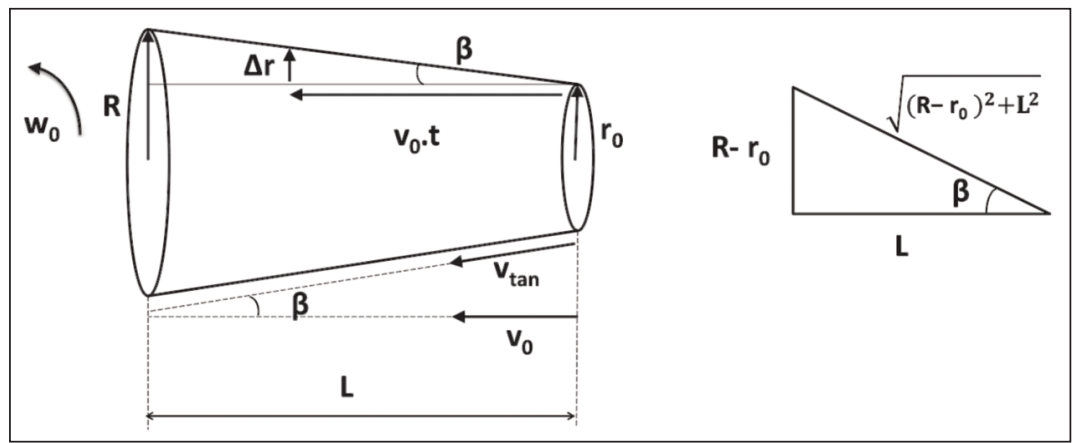

Fig. 3. Parameters on conical filament winding

$$
\begin{gathered}
\Delta r=v_{0} \cdot t \cdot \frac{R-r_{0}}{L} \\
r(t)=r_{0}+\Delta r=r_{0}+v_{0} \cdot t \cdot \frac{R-r_{0}}{L}
\end{gathered}
$$

If the angular velocity $w_{0}$ and the lateral velocity $v_{\tan }$ are constant, the winding angle according to local axis on surface is:

$$
\tan \alpha=\frac{r(t) \cdot w_{0}}{v_{0}}=\frac{\left[r_{0}+v_{0} \cdot t \cdot \frac{R-r_{0}}{L}\right] \cdot w_{0}}{v_{0}}
$$

If the lateral velocity $v_{0}$ is not constant and changed as a step function to $v_{f}$, then the differential equation similar to the equation 6 defines the time dependent response of the winding angle. The difference is; radius $r$ is not constant any more as in equation 6 , instead the expression in equation 15 must be used. Tangent $\alpha_{f}$ is also changing with time, but if the angle $\beta$ is small, the change can be omitted and the $\tan \alpha_{f}$ can be taken as constant to solve the integral.

$$
\begin{gathered}
-\frac{|O C|}{\left[r_{0}+v_{\operatorname{tanf}} \cdot t \cdot \frac{\mathrm{R}-r_{0}}{L}\right] \cdot w_{0}} \cdot \frac{\mathrm{d} a}{\mathrm{~d} t}=a(t)-\frac{|O C|}{\tan \alpha_{f}} \\
a(t)=|O C| \cdot\left[\left(\tan \alpha_{i}\right)^{-1}-\left(\tan \alpha_{f}\right)^{-1}\right] \cdot \\
\cdot \mathrm{e}^{-\frac{w_{0}}{|O C|}\left[r_{0} t+\frac{v_{\operatorname{tanf}} \cdot\left(R-r_{0}\right)}{2 L} \cdot t^{2}\right]}+\frac{|O C|}{\tan \alpha_{f}} \\
\alpha(t)=\tan ^{-1}\left\{\left[\left[\left(\tan \alpha_{i}\right)^{-1}-\left(\tan \alpha_{f}\right)^{-1}\right] \cdot\right.\right. \\
\left.\left.\cdot \mathrm{e}^{-\frac{w_{0}}{|O C|}\left[r_{0} t+\frac{v_{\text {tanf }} \cdot\left(R-r_{0}\right)}{2 L} \cdot t^{2}\right]}+\left(\tan \alpha_{f}\right)^{-1}\right]^{-1}\right\}
\end{gathered}
$$

In equation $v_{\text {tanf }}$ is the final tangential lateral velocity after the change of lateral velocity. The initial winding angle $\alpha_{i}$ and final winding angle $\alpha_{f}$ are found according to equation 16 as followed in equation 20 and 21 .

$$
\begin{aligned}
& \alpha_{i}(t)=\tan ^{-1}\left\{\frac{\left[r_{0}+v_{0} \cdot t \cdot \frac{R-r_{0}}{L}\right] \cdot w_{0}}{v_{\operatorname{tani}}}\right\} \\
& \alpha_{f}(t)=\tan ^{-1}\left\{\frac{\left[r_{0}+v_{f} \cdot t \cdot \frac{R-r_{0}}{L}\right] \cdot w_{0}}{v_{\operatorname{tanf}}}\right\}
\end{aligned}
$$

\section{Paraboloid mandrel}

Paraboloid mandrels can be used as heat shield or aerodynamic nose part for supersonic vehicles. Such as the approach of conical mandrels is derived from the cylindrical equations, same approach can be used to derive the paraboloid equations. The differential equation (equation 6 ) is taken and the radius expression of paraboloid is integrated, and then the equation is solved. Figure 4 shows the main parameters of paraboloid filament winding.

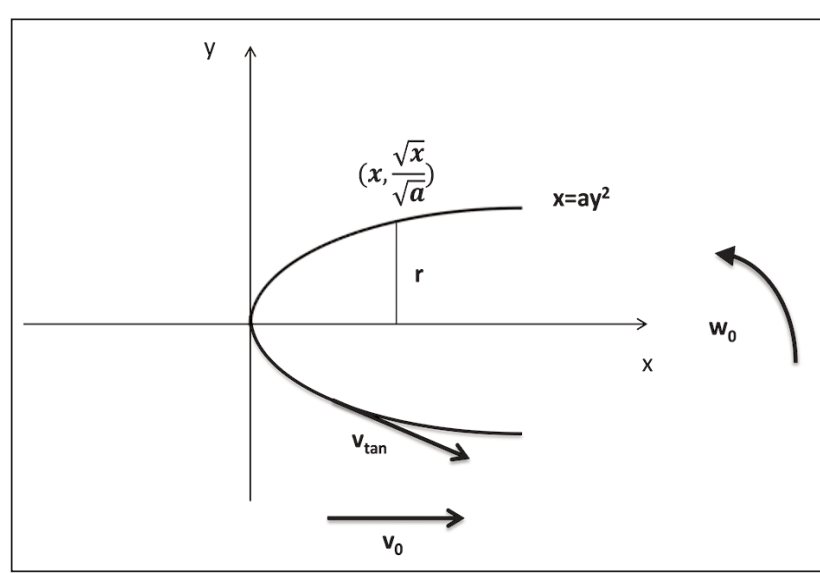

Fig. 4. Parameters on paraboloid filament winding

For the case of constant lateral guide velocity $v_{0}$ and angular velocity $w_{0}$ :

$$
\begin{gathered}
r=y=\frac{\sqrt{x}}{\sqrt{a}} ; \quad x=v_{0} \cdot t ; r(t)=\frac{\sqrt{v_{0}}}{\sqrt{a}} \cdot \sqrt{t} \\
\tan \alpha=\frac{r \cdot w_{0}}{v_{\tan }}=\frac{\sqrt{v_{0}}}{\sqrt{a}} \cdot \sqrt{t} \cdot \frac{w_{0}}{v_{\tan }}
\end{gathered}
$$

The relation between the lateral filament guide velocity $v_{0}$ and the lateral velocity on the surface of the paraboloid $v_{\tan }$ is defined by the derivative of the parabola equation.

$$
\begin{gathered}
y=\frac{\sqrt{x}}{\sqrt{a}} ; \frac{d y}{d x}=\frac{1}{2 \sqrt{a x}}=\tan \beta \\
v_{\tan }=\frac{v_{0}}{\cos \beta}
\end{gathered}
$$

$\operatorname{Cos} \beta$ in equation 25 can be found by drawing an imaginary right triangle by using the $\tan \beta$ expression from equation 24 . The opposite edge of the right triangle is " 1 " and the adjacent edge is " $2 \sqrt{\mathrm{ax}}$ ". The equation 25 becomes:

$$
v_{\tan }=\frac{v_{0} \cdot 2 \sqrt{a x}}{\sqrt{1+4 a x}}
$$

The radius equation (eq. 22) is inserted into the differential equation (eq. 6). 


$$
\begin{gathered}
-\frac{|O C|}{\frac{\sqrt{v_{0}}}{\sqrt{a}} \cdot \sqrt{t} \cdot w_{0}} \cdot \frac{\mathrm{d} a}{\mathrm{~d} t}=a(t)-\frac{|O C|}{\tan \alpha_{f}} \\
a(t)=|O C| \cdot\left[\left(\tan \alpha_{j}\right)^{-1}-\left(\tan \alpha_{f}\right)^{-1}\right] . \\
\cdot \mathrm{e}^{-\frac{2 w_{0} \sqrt{v_{\tan }} \cdot t^{3 / 2}}{3 \cdot|O C| \cdot \sqrt{a}}+\frac{|O C|}{\tan \alpha_{f}}} \\
\alpha(t)=\tan ^{-1}\left\{\left[\left[\left(\tan \alpha_{i}\right)^{-1}-\left(\tan \alpha_{f}\right)^{-1}\right] .\right.\right. \\
\left.\left.\cdot \mathrm{e}^{-\frac{2 w_{0} \sqrt{v_{\tan }} \cdot t^{3 / 2}}{3 \cdot|O C| \cdot \sqrt{a}}}+\left(\tan \alpha_{f}\right)^{-1}\right]^{-1}\right\}
\end{gathered}
$$

The integration constants containing initial winding angle $\alpha_{i}$ and final winding angle $\alpha_{f}$ can be calculated via equations 30 and 31 .

$$
\begin{aligned}
& \alpha_{i}(t)=\tan ^{-1}\left\{\frac{\left[\frac{\sqrt{v_{0}}}{\sqrt{a}} \cdot \sqrt{t}\right] \cdot w_{0}}{v_{\text {tani }}}\right\} \\
& \alpha_{f}(t)=\tan ^{-1}\left\{\frac{\left[\frac{\sqrt{v_{f}}}{\sqrt{a}} \cdot \sqrt{t}\right] \cdot w_{0}}{v_{\text {tanf }}}\right\}
\end{aligned}
$$

\section{RESULTS AND DISCUSSION}

A cylindrical base model is assumed to see the time dependent response of filament winding angle to changing lateral filament guide velocity. The radius of the cylinder $r$ is $10 \mathrm{~cm}$, angular velocity is $10 \mathrm{rad} / \mathrm{s}$, distance of filament guide to the mandrel $|\mathrm{OC}|$ is 20 $\mathrm{cm}$, initial winding angle $\alpha_{i}$ is $30^{\circ}$ and the final winding angle $\alpha_{f}$ is $60^{\circ}$. According to equation 11, figure 5 shows how the filament winding angle responds to a step-wise changing of velocity.

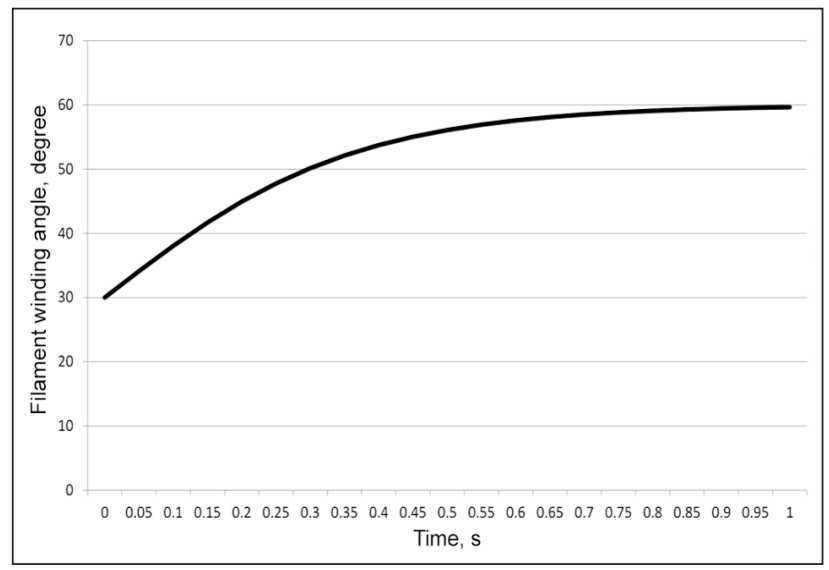

Fig. 5. Change of filament winding angle on cylindrical mandrel: $30^{\circ}-60^{\circ}$ base model

Figure 6 shows the effect of increased angular velocity from $10 \mathrm{rad} / \mathrm{s}$ of base model to $20 \mathrm{rad} / \mathrm{s}$. As expected, the reaction of filament angle is faster and about half of the time elapses to reach the final angle compared to the base model of figure 5. Figure 7 shows similarly the effect of increasing mandrel radius from $10 \mathrm{~cm}$ to $30 \mathrm{~cm}$. Increasing of mandrel radius has the same accelerated reaction effect as the increasing angular velocity.

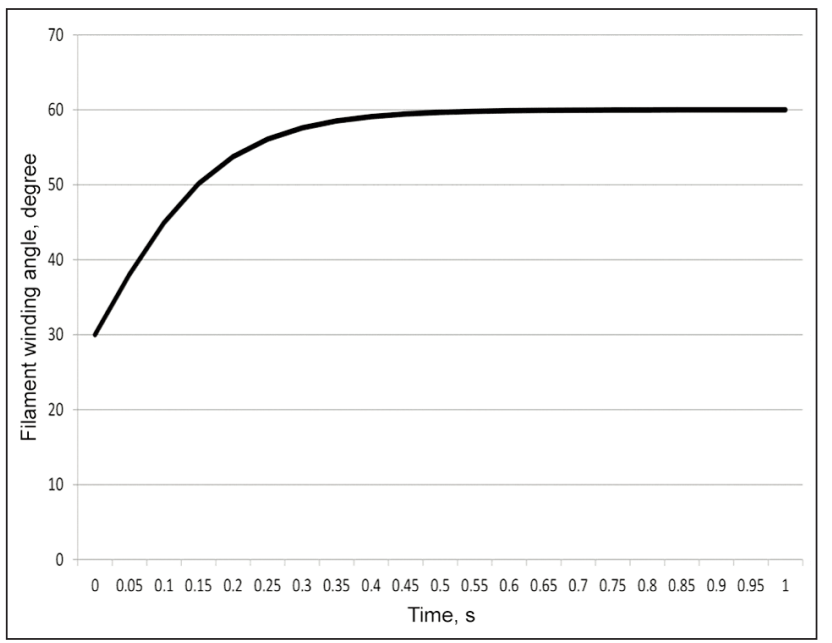

Fig. 6. Change of filament winding angle on cylindrical mandrel: $30^{\circ}-60^{\circ}$ with increased angular velocity $w$

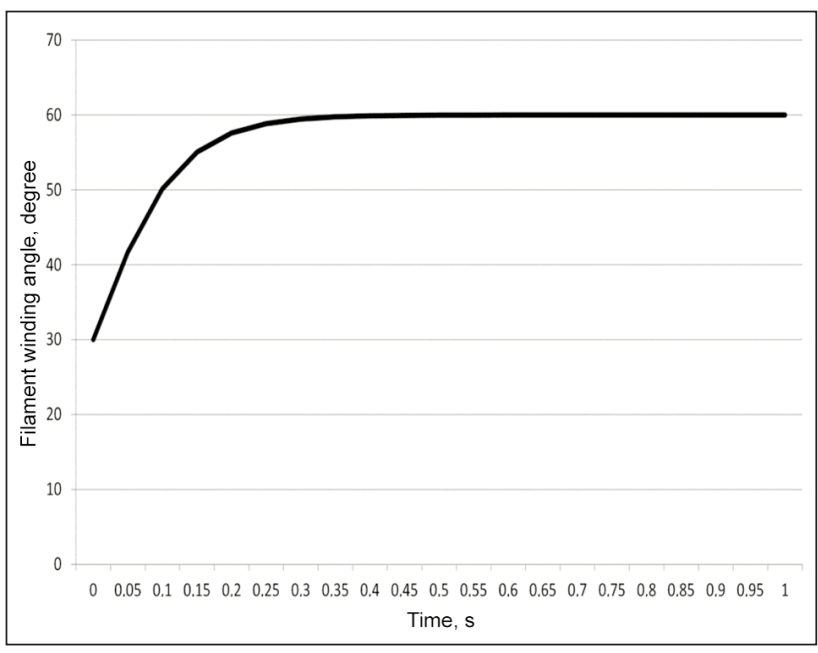

Fig. 7. Change of filament winding angle on cylindrical mandrel: $30^{\circ}-60^{\circ}$ with increased radius $r$

If the filament angle changes $30^{\circ}-60^{\circ}$ of base model is reversed to $60^{\circ}-30^{\circ}$, the resulting curve is depicted in figure 8 . The reaction time is a bit less compared to $30^{\circ}-60^{\circ}$ change. Changing from a higher winding angle to lower takes slightly less time than vice versa. A conical mandrel is assumed with parameters of narrow end radius $10 \mathrm{~cm}$, large end radius $R 20 \mathrm{~cm}$, mandrel length $100 \mathrm{~cm}$, angular velocity $w 10 \mathrm{rad} / \mathrm{s}$, final tangential velocity $v_{\operatorname{tanf}} 10 \mathrm{~cm} / \mathrm{s}$, distance of filament guide to the mandrel $|\mathrm{OC}| 20 \mathrm{~cm}$, initial winding angle $\alpha_{i} 30^{\circ}$ and the final winding angle $\alpha_{f} 60^{\circ}$. Figure 9 demonstrates the angle response curve, as the conicity of the mandrel is not high, the curve looks similar to base model cylindrical mandrel, however the calculated values are slightly different due to the equation 19. 


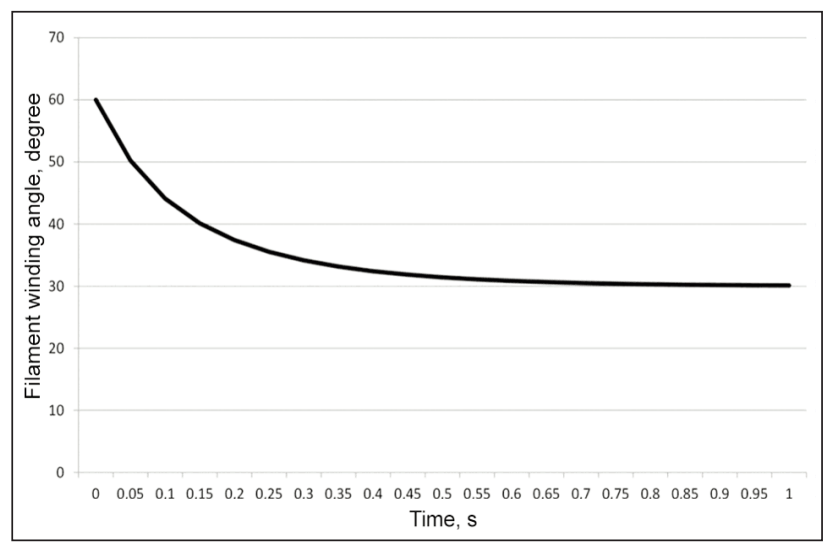

Fig. 8. Change of filament winding angle on cylindrical mandrel: $60^{\circ}-30^{\circ}$ base model

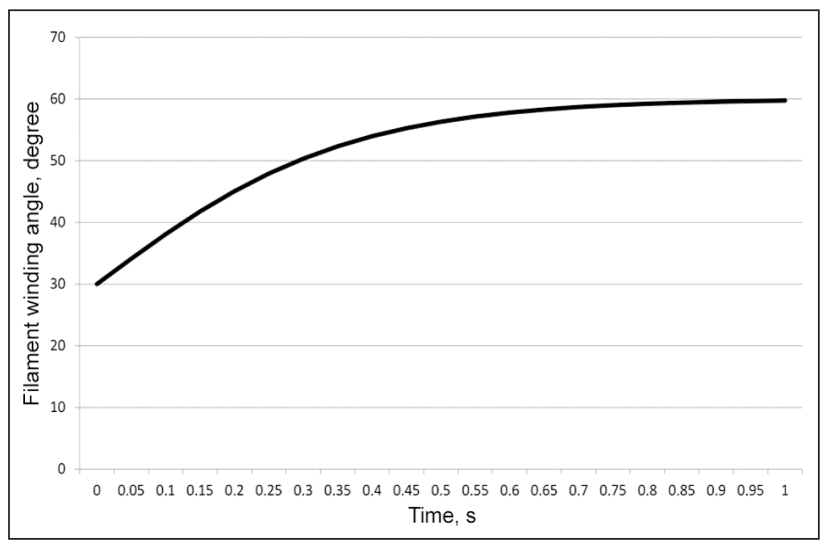

Fig. 9. Change of filament winding angle on conical mandrel: $30^{\circ}-60^{\circ}$

Figure 10 shows the angle response curve on a paraboloid mandrel. The parameters are selected likewise to ease the comparison with previous models of figures $5-9$. The angular velocity $\mathrm{w}$ is $10 \mathrm{rad} / \mathrm{s}$, final tangential velocity $v_{\operatorname{tanf}}$ is $10 \mathrm{~cm} / \mathrm{s}$, distance of filament guide to the mandrel $|\mathrm{OC}|$ is $20 \mathrm{~cm}, a$ is 2 at the curve $x=2 y^{2}$, initial winding angle $\alpha_{i}$ is $30^{\circ}$ and the final winding angle $\alpha_{f}$ is $60^{\circ}$. According to equation 29, figure 10 shows how the filament winding angle responds to a step-wise changing of velocity. The shape of the paraboloid flattens the reaction curve of winding angle.

The cylindrical, conical and paraboloid models all have the common property of circular cross-section.

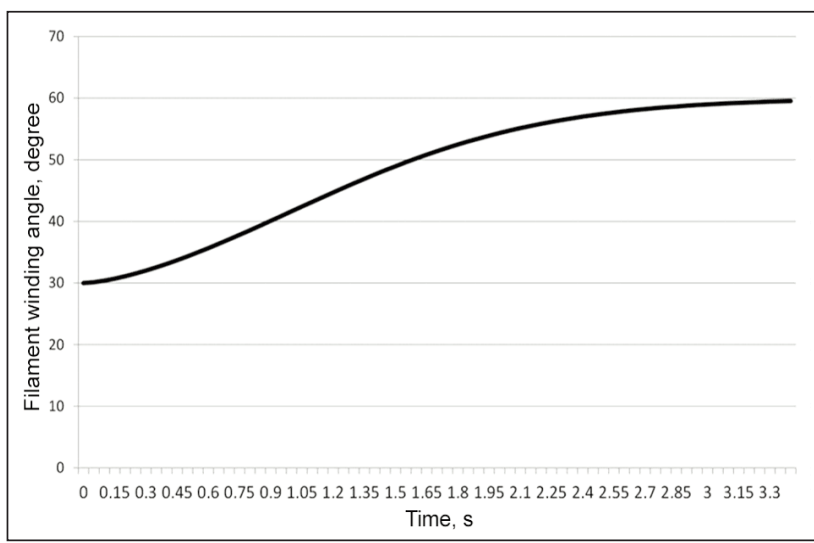

Fig. 10. Change of filament winding angle on paraboloid mandrel: $30^{\circ}-60^{\circ}$

On the other hand, the elliptical mandrel yields a changing radius in the cross-section. The elliptic integral of type 2 (equation 36) does not have an analytical solution but it can only be approximated with a series expansion (equation 41). Due to the approximation, however, the time parameter " $\mathrm{t}$ " disappears from the equation and the responding character cannot be seen, instead if the angle is changing from $30^{\circ}-60^{\circ}$, then the integral approaches to the mean value of $45^{\circ}$. Therefore, this method works only for mandrels with circular cross-sections, for other types of geometries a different approach is necessary to be developed.

\section{CONCLUSIONS}

An analytical approach is derived for the filament winding angle response on cylindrical, conical, paraboloid and elliptic cylindrical mandrels. Increasing of radius and angular velocity decreases the time elapsed to reach the final winding angle. Independent of the type of the mandrel, if the cross-section of the mandrel is circular, the method delivers applicable results. On the other hand, the method is not applicable to mandrels with cross-sections other than circular form because of the varying radius in the crosssection. A new method should be developed for mandrels with cross-sections of noncircular forms. This method provides an analytical calculation of winding angle for filament wound textile reinforced composites and structures.

\section{REFERENCES}

[1] Spencer, B., Hull, D., Effect of winding angle on the failure of filament wound pipe, In: Composites, 1978, 9, 4, 263-271

[2] Mistry, J., Theoretical investigation into the effect of the winding angle of the fibres on the strength of filament wound GRP pipes subjected to combined external pressure and axial compression, In: Composite Structures, 1992, 20, 2, 83-90

[3] Kessels, J.F.A., Akkerman, R., Prediction of the yarn trajectories on complex braided preforms, In: Composites, Part A. Applied Science and Manufacturing, 2002, 33, 8, 1073-1081

[4] Zhang, Q., Beale, D., Broughton, R.M., Analysis of Circular Braiding Process, Part 1: Theoretical Investigation of Kinematics of the Circular Braiding Process, In: Journal of Manufacturing Science and Engineering, 1999, 121, 3, 345-350 
[5] Zhang, Q., Beale, D., Broughton, R.M., Adanur, S., Analysis of Circular Braiding Process, Part 2: Mechanics Analysis of the Circular Braiding Process and Experiment, In: Journal of Manufacturing Science and Engineering, 1999, 121, 3, 351-359

[6] Nishimoto, H., Ohtani, A., Nakai, A., Hamada, H., Prediction Method for Temporal Change in Fiber Orientation on Cylindrical Braided Preforms, In: Textile Research Journal, 2009, 80, 9, 814-821

Author:

\section{AHMET REFAH TORUN}

Adana Alparslan Türkeş Science and Technology University, Faculty of Aerospace, Aerospace Engineering,

Çatalan Caddesi 201/1, 01250, Adana, Turkey

Corresponding author:

AHMET REFAH TORUN

e-mail: artorun@atu.edu.tr 